\title{
CHEMICAL METHODS FOR ASCERTAINING THE LIME REQUIREMENT OF SOILS.
}

By H. J. Wheeleq, B. I, Hartwell, and C. L. Sargent.

Received February 20, r900.

HAVING recognized the occurrence of an injurious degree of 7 acidity in the upland soils of Rhode Island and other states, even upon steep hillsides, it became important to ascertain by chemical means if possible the relative lime requirement of different soils. If such could be done in a simple and effective way, then one would be in a position to recommend satisfactorily what amount of lime to use per acre without resort to field tests.

TESTS BY BLUE LITMUS PAPER.

Perhaps the simplest, though nevertheless a very satisfactory test, is that made by bringing a piece of blue litmus paper in contact with the moistened soil and observing the intensity and rapidity of the reddening thus produced. Though unsatisfactory, in view of its not being a quantitative test, much valuable information regarding the amounts of lime which should probably be used, may thus be obtained, after some experience, by one who is a careful observer. Wahnschaffe' in speaking of this reaction says, "since the free carbonic acid of the soil reddens the paper, one must allow it to dry and observe whether or not the red color is still visible." Roscoe and Schorlemmer" state that "carbonic acid readily decomposes into water and carbon dioxide. In consequence of this, litmus paper which has been turned red in the aqueous acid, becomes blue on drying." They then immediately add that the reddening of litmus solution may be brought about by conducting into it carbon dioxide, but that upon heating the solution the carbon dioxide is expelled, and after boiling a few seconds the liquid again becomes blue. In Watts' Dictionary of Chemistry ${ }^{3}$ it is stated that an "aqueous solution of $\mathrm{CO}_{2}$ turns blue litmus paper wine-red; the blue color returns on exposure to air." It seems probable that on account of the well-known reaction of litmus solution whereby, when reddened by carbon dioxide gas, it returns to a blue color, it has

1 Anleitung zür wissenschaftlichen Bodenuntersuchungen, Berlin (1887), p. 56 .

2 "Treatise on Chemistry," I, New York (1888), p. 638.

8 Vol. I, London (1890), p. 695. 
I 54 H.J. WHEELER, B. L. HARTWEI, AND C. I. SARGENT.

been assumed that a similar reaction would necessarily take place when operating with litmus paper. This conclusion seems exceedingly probable since the writers have been unable to find references in the literature to any definite tests bearing upon this point. It is possible also that tests, if made, were carried out by operating with carbonic acid upon small sections of a piece of litmus paper, in which case, sufficient alkali might diffuse from the surrounding paper into the section acted upon, to neutralize the carbonic acid still remaining. That such a return of the blue color may result when the entire portion of the litmus paper is not subjected to treatment with acid, has been demonstrated by us upon commercial paper in the case of carbonic acid and of very dilute citric acid.

Owing to the action of the fingers upon blue litmus paper and the bleaching action of the sun, the test would be far simpler and more reliable in the hands of practical farmers if it were not necessary to wait for the paper to dry before drawing conclusions as to the probable needs of the soil. In view of the fact that some of the conditions prevailing when working with litmus paper are so different from those existing when employing the solution, it seemed probable that blue litmus paper, if entirely reddened by carbonic acid, and dried with the promptness that would ordinarily be expected, would not return to its original blue color. Dr. H. E. Stockbridge told one of us that he was under the impression that he once found this to be the case. In order to test this matter thoroughly, trials were made with ordinary commercial blue litmus paper and also with lots of paper prepared from solutions made according to Classen' and Sutton. ${ }^{2}$ The carbonic acid was prepared by expelling the carbon dioxide from an aqueous solution of chemically pure sodium bicarbonate by simply boiling without the use of acid. A return condenser was employed and the carbon dioxide was washed in distilled water before its collection. Steam, generated from the distilled water which was used subsequently to dissolve the sodium bicarbonate, was first passed through the entire apparatus for some time and the distillate tested to insure the absence of

1 Böckmaun's "Chemisch-technische Untersuchungsmetboden", Vol, I, Berlin (1888), p. 97

2 The third method. Sutton's "Handbook of Tolunetric Analysis", London (I $88_{2}$ ), p. 31 . 
volatile organic acids. Treated with carbonic acid prepared in this way all three lots of blue litmus paper were permanently reddened when dried naturally in the open air or in a room free from acids and ammonia. It is evident therefore that when dried naturally the carbon dioxide is not lost to any great extent or else the red, acid coloring-matter of the litmus is too firmly fixed upon the fiber of the paper, to permit of its reunion with the base, a change which would have resulted in the case of a solution, after the expulsion of the carbon dioxide. Coupling with these results the fact that so long as a liberal amount of calcium carbonate is present in a soil, the presence of carbonic acid tends to increase rather than lessen the tendency toward an alkaline reaction ${ }^{1}$ (a point proved by us experimentally in the laboratory) it must be evident that the indication of acidity afforded by a piece of blue litmus paper is sufficient to show a deficiency of calcium carbonate or other basic ingredients in soils, without first allowing the paper to dry, as suggested by Wahnschaffe.

TESTS BY EXTRACTION WITH AMMONIA.

Müntz ${ }^{2}$ states that it is easy to distinguish whether or not a soil is acid, since if such is the case it imparts a black color to ammonium hydroxide when the two are brought in contact. He adds that in the case of soils which are not acid, the organic matter is in an insoluble combination with lime and consequently yields nothing to ammonium hydroxide. The same has been found by us to be the case with a sample of fertile adobe soil kindly forwarded by Professor Goss, from New Mexico. Similar observations have also been made on one Massachusetts and two Rhode Island soils where wood ashes or calcium carbonate in some form had been applied to the land with such frequency as to entirely overcome its acid reaction upon blue litmus paper. Snyder, ${ }^{3}$ however, calls attention to a soil which he says contained 3.I 5 per cent. of lime $(\mathrm{CaO})$ and 4 . I9 per cent. of carbon dioxide, and yet when treated with ammonium hydroxide for the determination of the so-called "free humic acid" yielded a dark brown extract amounting to from 0.3 to 0.4 of a

1 Compare Detmer Die naturwissenschaftlichen Grundlagen d. allg. landw. Bodenkunde ( 1876 ), p. 45 I; also Stöckhardt, Jabrbuch für Agriculturchemie (1866), p. Io.

2 Encyclopédie Chimique, 4, Pt. 4, p. 18.

8 Bulletin No. 56, Chemical Division, United States Department of Agriculture, Washington, D. C., I899. 


\section{I56 H. J. WHEELER, B. I. HARTWELL, AND C. L. SARGENT.}

per cent. This would tend to throw some doubt upon the reliability of the treatment with ammonium hydroxide as a means of arriving at the lime requirements of all soils, though it is not improbable that for soils of certain sections of the United States which are possessed of definite characteristics, the treatment may be of considerable value as was the case in the particular acid soils, for which Müntz employed the method. The details of the method as proposed by Müntz ${ }^{1}$ are as follows: To zo grams of powdered soil, add $50 \mathrm{cc}$. of concentrated ammonium hydroxide. Allow it to stand for from two to three days in a warm place. Agitate frequently and at the end of the period make the volume up to $\mathrm{I}$ liter. It is then shaken and allorved to subside for twenty-four hours. To $500 \mathrm{cc}$. of the liquid add sufficient hydrochloric acid to give a strong acid reaction in order to precipitate the humus, which carries with it some mineral matter. After the precipitate has subsided, decant the supernatant liquid, collect on a filter, dry and weigh in a meighing bottle, incinerate, deduct the ash, and the "free humic acids" are thus obtained by difference. In order to determine what influence, if any, the use of concentrated ammonium hydroxide might have upon the results compared with dilute solutions, a sample of upland soil was tested by the above method and yielded r.oo per cent. Treated for the same time with the same amount of ammonium hydroxide previously diluted to $500 \mathrm{cc}$. (containing 1.I3 per cent. of ammonia) it also yielded $\mathrm{I} .00$ per cent. The same soil treated for a like time with $500 \mathrm{cc}$. of the same solvent containing 2.4 per cent. of ammonia yielded I.00 per cent. Employing sufficient concentrated ammonium hydroxide so that after diluting to $500 \mathrm{cc}$. it would have the same strength as in the lastmentioned instance, it yielded, treated for the same time, I.03 per cent. It appears therefore that in the case of ordinary soils the strength of the solvent within reasonable limits is not an essential feature, and that the solution usually employed in total humus determinations may be used here with equal propriety.

THE METHOD OF HOLLEMAN FOR DETERMINING THE LIME REQUIREMENTS OF STIFF CLAY SOILS.

Holleman ${ }^{2}$ in searching for the cause of the occasional

1 Encyclopédie Chimique, 4, Pt. 4, p. I 82.

2 Die landw, Versuchs-stationen $4 \mathrm{I}$ (1892), p. $3 \mathrm{~S}$. 
ineffectiveness of gas-lime upon certain stiff clays in Holland concluded that it might be due to the presence in them of considerable calcium carbonate. He thereupon made determinations of the lime removable by water and by water saturated with carbon dioxide. The water-soluble lime was determined as follows: Twenty grams of air-dried soil were digested with frequent shaking, at ordinary temperature, for forty-eight hours with I liter of distilled water. Five hundred grams of the filtrate to which a few drops of acetic acid had been added were evaporated, the residue taken up in water; and first a little acetic acid and then a measured quantity of $\frac{N}{10}$ solution of ammonium oxalate were added and the volume made up to roo cc. After filtration, the excess of oxalic acid is estimated by titrating with a $\frac{N}{10}$ solution of potassium permanganate. For determining the lime soluble in carbonic acid 20 grams of air-dried soil are taken and sufficient distilled water added to make up I liter; it is then saturated with carbon dioxide and after twenty-four hours filtered and treated as described above. From the data obtained by Holleman, he concluded that where extraction with carbonic acid removed 0.15 per cent., or less, of calcium oxide, stiff clay soils would be benefited by liming.

In order to test the applicability of this method to the acid sandy and clayey loam soils of our State, two samples were selected, the first being from a farm in Warren, R. I., where, with the same manurial and other treatment, the yield of beets upon the unlimed plot was 272 pounds against 329 pounds upon the limed plot. The second soil was from Foster Center, R. I., where under the same conditions the yield of beets upon the unlimed plot had been 36.6 pounds and upon the limed one 143.4 pounds. In making the test of the soil from Warren, 80 grams of soil were employed, and in that from Foster Center, 40 grams. The soil was placed in each case in a flask to which I liter of distilled water, saturated with carbon dioxide, was added. The flask was agitated frequently and the treatment continued for forty hours. Four hundred cc. of the extract were evaporated to dryness, taken up in water and a little acetic acid, $\frac{N}{10}$ ammonium oxalate was added, and after filtration, the whole was made up to $200 \mathrm{cc}$. Aliquot parts of this solution were titrated with Io potassium permanganate, after acidulation with sulphuric acid. In 
one instance the small amount of acetic acid was removed by evaporation to dryness before adding sulphuric acid and titrating without practically affecting the results. Allowing for the blank found, the amount of calcium oxide thus determined amounted in the Foster Center soil to 0.0360 per cent. In the case of the Warren soil, which was treated in the same manner, the amount of calcium oxide removed from the soil was found to be 0.0287 .

The Warren soil extracted with distilled water, in a similar manner for forty-eight hours, yielded 0.0120 per cent. of calcium oxide.

From these tests it will be seen that the soil which was least benefited by lime, yielded less lime than the other. It is possible that the use of double the amount of soil in the last instance may have depressed the result somewhat as compared with the other, though it is not likely that the difference caused by this factor would, under the circumstances, have been readily appreciable. At all events the amount of lime removed in the highest case was only about one-fifth of that below which Holleman found lime useful on stiff clays.

It appears, therefore, in view of the marked degree of acidity of those of our soils which it seemed desirable to test as to their lime requirements, that this method is probably not of great value. It is regretted, nevertheless, that the pressure of routine work has prevented making further tests of the applicability of the method to our special needs, particularly with greater attention to maintaining the saturation of the carbonated water.

THE METHOD OF TACKE FOR DETERMINING THE FREE HUMUS

ACIDS IN THE PEAT (MOORBODEN) SOILS

OF NORTH GERMANY.

Tacke ${ }^{1}$ states that no method is known for determining quantitatively the acidity of soils, and calls attention to the desirability of possessing a satisfactorily exact method for the purpose. He discusses the difficulties in the way of determining the acidity by various ways which would naturally suggest themselves, and finally gives a method which yielded good results. It is impossible to give the method satisfactorily in

1 Chem. Ztg., No. 20, 1897, p. 174 . 
detail without reproducing the illustration of the apparatus which he employed. Essentially the method consists in expelling the carbon dioxice from calcium carbonate brought in contact with the soil at ordinary room temperature. Hydrogen is passed over the soil for some time in the apparatus, then finely divided calcium carbonate, shaken up with water, is introduced and allowed to act upon the soil for two and a half hours or longer as desired. The carbon dioxide disengaged is taken as a measure of the acidity of the soil, the amount being determined by passing it through a Pettenkofer tube containing $\frac{N}{5}$ or $\frac{N}{10}$ sodium hydroxide. The liquid is finally removed from the tube, taking care in regard to the absorption of carbon dioxide from the air, barium chloride then added and the solution titrated with $\frac{N}{5}$ or $\frac{N}{I 0}$ hydrochloric acid using phenolphthaleïn as an indicator with attention to the points brought out by the investigations by Küster and by Lunge. ' Determined in this way, using soil in its natural state, the amount of acid reckoned as carbonic acid, represented by Ioo parts of dry material, amounted in the case of various peat soils to from I.72I to 2.240 per cent. The method gives promise of much value for such soils as a guide to the amount of lime which they should receive. In April, 1895, experiments were begun by one of us for the purpose of ascertaining if the amount of carbon dioxide liberated from calcium carbonate upon heating it with upland acid soils in the presence of water, could be used as a guide to the amount of lime to apply to them. Owing to the pressure of routine matters, this work was several times taken up and then soon discontinued. Not having satisfactorily perfected a method at the time Tacke's results were published, it was decided to see if his method was applicable to our upland soils. Two unlimed soils were selected for the trial, the one from land where sodium nitrate had been applied for several years and the other from land where the manuring had been identical except that the same quantity of nitrogen had been applied in ammonium sulphate. The yields of most crops had been for several years far better upon the former than upon the latter plot of land.

1 Chem. Ztg. Repert, 29, 282 (1896); Ztschr, anorg. Chem., 13, 127 pp. (:896).

2 Bestimmung von Caustischen und Kohlensauren Alkalien, G. Lunge, Ztschr. angew. Chem., 4 I (1897). 
The percentage of carbon dioxide obtained by treatment for three hours, calculated to dry soil, was 0.039 for the soil which had received sodium nitrate and 0.067 for the one which had received ammonium sulphate. In other words the results stood in the same relation as the yields. Taking into account the fact that the soils contained nearly 4 per cent. of humus and from 1.25 to 1.55 per cent. of humus immediately soluble in ammonium hydroxide, it is evident that the action of this class of soils upon calcium carbonate, at ordinary temperature, is far less vigorous than that of the peat soils tested by Tacke. The percentages obtained by this method are so small, and the element of error proportionately so great, that the indications are not particularly favorable to its use with soils of the character to which it was hoped the test would apply.

\section{DETERMINATION OF TOTAL HUMUS.}

The determination of total humus could only be expected to throw light upon the lime requirement of soils where marked acidity of the soil exists, and while it might even then bear no relation to the benefit to be derived from liming, it was deemed of interest to ascertain by actual tests what relation, if any, would be found. Combined with the tests to determine the amount of humus soluble in ammonium hydroxide, without previous extraction of the soil with hydrochloric acid, it was also possible to learn if there appeared to be any relation between the gain from liming and the percentage of the total humus, which was directly soluble in ammonium hydroxide.

The method employed was essentially that of Grandeau as modified by Huston and McBride.' Twenty grams of soil were first extracted with hydrochloric acid as proposed by Hilgard ${ }^{2}$ with the employment of an automatic washing apparatus, until no further reaction for lime was obtainable in the wash solution. After the removal of the acid by successive washings with distilled water, the material was extracted with ammonium hydroxide, aliquot portions of the extract evaporated to dryness, incinerated, the ash deducted and the humus thus obtained by difference. The relation between the results obtained and the data

I Wiley's "Principles and Practice of Agricultural Analysis," Vol. I, $327,328$.

2 Ibid., p. 325. 
secured in actual experiments with lime upon several soils will be discussed later.

DETERMINATION OF THE AMOUNT OF IIME REMOVABLE BY HYDROCHLORIC ACID.

In soils containing some calcium carbonate, a number of methods have been proposed for arriving at their probable need of lime. Among others, Mondesir ${ }^{1}$ gives a method by which he proposes to ascertain the active calcium carbonate in soils, since, as he says, soils may contain considerable of this substance, perhaps so surrounded by particles of clay that for practical purposes it is of little or no use, and nevertheless stand in need of lime. In our own soils which have been shown to contain practically no calcium carbonate, it must be evident that such methods can be of no avail. If the need of lime, in soils of the character under consideration, is determinable by the quantity of lime present, regardless of its form, then extraction with a strong mineral acid ought to serve as a fair basis for arriving at the lime requirement of the soil. Various methods of treatment, with different kinds, strengths, and volumes of acids have been proposed. For the purpose in hand the method ${ }^{2}$ of the Association of Official Agricultural Chemists of the United States was followed, the digestion of the soil (Io grams) having been carried on for ten hours with roo cc. hydrochloric acid (I, I I $5 \mathrm{sp}$. gr.) at the temperature of boiling water with the employment of a return condenser. The data thus secured, with soils tested in a practical way with lime, in the field, are given later in tabular form in which connection they will be discussed.

\section{ACIDITY BY TITRATION.}

If means could be devised for determining the relative acidity, or the lime requirements of soils by titration, the matter would be rendered extremely simple and the tests could be made in great numbers at small expense. Owing to the extreme insolubility of the acids, or acid compounds of the soil, the titration of a watery extract of the soil could not be expected to furnish any very valuable data. In order to obtain, if possible, restults which might indicate in some measure the probable affinity for lime

1 Anuales de la Science Agron., 2, 270 (1887).

2 Bull. 46, Div, of Chemistry, U. S. Dept. of Agriculture, pp. 39, 40. 
(the substance which would usually be applied in the neutralization of soils), a study was made of the action of lime-water, the strength of the supernatant liquid, after contact with the soil for some time, being determined by titration. Air-dried soil was employed so as to eliminate any possible influence which might arise from drying at higher temperatures. Owing to the fact that these trials were only preliminary, and on account of the slight variation in the moisture of the soils examined which varied but little from 2.25 per cent., no correction has been applied to the results for the moisture contained in the soil itself. Ten grams of air-dried soil were brought in contact with $50 \mathrm{cc}$. of lime-water in a small flask. The flask was securely corked and occasionally agitated. At the end of about twenty hours the supernatant liquid was passed rapidly through a dry filter, an excess of hydrochloric acid of known strength ( $3 \mathrm{cc}$. neutralizing $36.1 \mathrm{cc}$. of the lime-water) added and the amount of unneutralized acid determined by titration with lime-water. In this way the volume of lime-water neutralized by Io grams of the air-dried soil was indirectly determined. With the same soil more lime-water was required, without exception, where it had remained unlimed, than where lime had been applied. In the comparison of two unlimed soils manured alike excepting that one had received its nitrogen for several years in sodium nitrate and the other in ammonium sulphate, the differences in the amounts of lime-water neutralized were not always in harmony with, nor were they marked enough to accord at all with the experience obtained in tests of the soils made by plants themselves. In a comparison of limed and unlimed soils it was found that by employing a greater amount of lime-water $(75 \mathrm{cc}$.) greater differences were obtained than by the use of but $50 \mathrm{cc}$. Possibly the use of even a somewhat greater amount would have given even better comparative results. Trials were also made, employing hydrochloric acid twenty times as dilute as that first tried. Coralline was used as an indicator, and though far from satisfactory in some respects, it was the only one tried which proved at all effective.

The preliminary trials not having indicated any particular general value of such a method, a trial of ammonium hydroxide was next made. 
TITRATION TESTS BY MEANS OF AMMONIUM HYDROXIDE.

A number of preliminary tests gave indications that the use of ammonium hydroxide in place of lime-water, was capable of giving results more nearly in accord with those obtained by plant tests. The method finally used was as follows: Fifteen grams of air-dried soil were placed in a glass flask and $100 \mathrm{cc}$. of about $\frac{N}{I 0}$ ammonium hydroxide and $100 \mathrm{cc}$. of distilled water added. This was allowed to stand at the ordinary temperature of the laboratory for about forty-two hours, with frequent agitation during the earlier portion of the time. After it had finally been allowed to settle, a definite amount of the supernatant liquid was treated with hydrochloric acid (about $\frac{N}{2}$ ) at the rate of five $c c$. for each $20 \mathrm{cc}$. of the liquid, and made up to a given volume. After the precipitated humus had subsided, aliquot portions of the solution $(5 \circ \mathrm{cc}$.) were titrated with ammonium hydroxide, using coralline as an indicator. Since by this treatment some portion of the organic acids may be dissolved by the ammonia, the method cannot give an absolute idea of the acidity of a soil. On the other hand, a method which determines the humus immediately soluble in ammonium hydroxide before extraction with bydrochloric or other strong acid, gives no indication of the acidity represented by acid inorganic compounds. Possibly if the amount of humus soluble in ammonium hydroxide were determined, and likewise the amount of ammonia held at the same time in combination by the insoluble residue, the combined data might furnish a better guide than either one alone. Unfortunately the occasional opportunities available for conducting such investigations have not yet permitted a study of this question.

In order to ascertain what effect a variation in the strength and volume of the ammonium hydroxide and the volume of soil might have, a given ${ }^{1}$ soil was tested in various ways.

(I) Twenty grams of soil were treated with $100 \mathrm{cc}$. of ammonium hydroxide diluted with a like quantity of water.

(2) Twenty grams of soil were treated with $50 \mathrm{cc}$. of ammonium hydroxide diluted with $\mathrm{I} 5 \mathrm{O} \mathrm{cc}$. of water.

1 Berthelot aud Andre (Ann.chim. phys., 7th Series, 1, 286 (1894)) in operating upon organic residues from soils treated with hydrofluoric acid, state that the amount of potassium oxide held by the organic matter varied with the strength of the potassium hydroxide with which it was treated. 
I64 H. J. WHEELER, B, L. HARTWELL, AND C. L. SARGENT.

(3) Twenty grams of soil were treated with $200 \mathrm{cc}$. of ammonium hydroxide.

(4) Twenty grams of soil were treated with I $50 \mathrm{cc}$. of ammonium hydroxide.

(5) Fifteen grams of soil were treated with roo cc. of ammonium hydroxide.

The following were the amounts of ammonium hydroxide retained in combination by the soil calculated in each case to ro grams of substance.

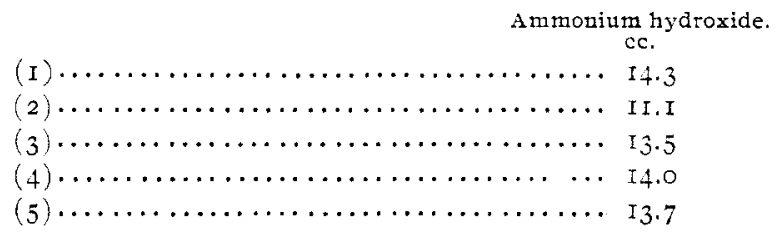

It will be seen from a careful examination of the data that they give some indication that only the weakest solution materially affected the results.

The trials of a number of Rhode Island soils by this method as described on page $\mathrm{I} 7 \mathrm{O}$ are given in a subsequent table where the data may be compared with those obtained by other chemical methods and with the actual gains in yield of beets, obtained by the employment of lime.

METHOD FOR DETERMINING THE LIME REQUIREMENT OF SOILS BY COMPARING, UNDER IDENTICAL CONDITIONS, THE COLOR OF AN AMMONIUM HYDROXIDE EXTRACT OF SOILS OF UNKNOWN CHARACTER WITH ONE OF KNOWN CHARACTER.

The method employed was to treat in a warm room like amounts of soil with like volumes of ammonium hydroxide (containing about 2.4 per cent. of ammonia) for two days with occasional agitation. The small amount of water contained in the air-dried soil itself has been shown to exert no appreciable effect upon the result so that for approximate comparisons, drying a portion of the soil at a high temperature and making allowances for the water in the soil, is unnecessary. The colors of the solutions are finally compared and if darker than the standard, they are diluted with water to match it, or if lighter in color some of the standard solution prepared from the 
soil of known character, is similarly diluted until it matches the one with which the comparison is being made. The amount of dilution in either case measures the excess or deficiency of color as compared with the standard. It was thought that certain weighable matters might be extracted by ammonium hydroxide from unhumified plant residues which might not color the solution to the same extent as the matter which is actually humified. In such a case, this method might perhaps give better indications than that as employed by Miintz (see page ${ }^{55}$ ). The possible variation in color of the individual ingredients of the complex, which is classed as humus, may in some cases seriously interfere with the use of the method.

The rapidity with which a large number of comparative determinations can be made after the material has settled, is a strong point in its favor as compared with the method of Muintz. The results obtained by both methods may be compared below in connection with those obtained in actual plant tests upon limed and unlimed soil.

ATTEMPTS TO DETERMINE THE LIME REQUIREMENT OF SOILS BY MEASURING THE CARBON DIOXIDE EXPELLED UPON HEATING A GIVEN QUANTITY OF SOIL, IN THE PRESENCE OF WATER, WITH CALCIUM CARBONATE OR WITH SODIUM CARBONATE.

This work was begun in April 1895 , at which time Tacke's method of treating peat soils at ordinary temperatures with calcium carbonate, had not been published. No notice of similar attempts to arrive at the lime requirement of soils having been found, the line of work was apparently wholly new and had to be conducted without the aid of any previous experience.

The first soil selected for this work was from the permanent experimental plot No. 23, which had been manured annually beginning with the year I893, with the following commercial materials ; viz., dissolved bone-black, potassium chloride and ammonium sulphate. The same arrangement was employed for the absorption of the carbon dioxide as is customary in ordinary determinations of carbon. As a preliminary trial 40 grams of soil, containing 24 per cent. of water capable of being driven off at $100^{\circ} \mathrm{C}$., were placed in a Wolff flask and heated, in the 
presence of water, with 4 grams of calcium carbonate. On account of the rapid evolution of carbon dioxide, the heating had to be conducted with the utmost care, as the boiling-point was approached, in order that the gas might be entirely absorbed.

A blank test with a definite amount of water and 80 grams of the soil (passed through a sieve containing holes $\frac{1}{2} 5$ of an inch in diameter) gave 0.0124 gram of carbon dioxide. A blank test with the water and 8 grams of calcium carbonate yielded 0.002 gram of carbon dioxide. Assuming that no carbon dioxide came from the calcium carbonate, 80 grams of the soil must have yielded upon heating in the manner described but (0.0124-0.002) 0.0104 gram of carbon dioxide.

Eighty grams of soil were heated with the same amount of water and calcium carbonate, and kept at the boiling-point until the evolution of gas seemed to have become practically constant and but very limited in amount. The carbon dioxide yielded, amounted to 0.338 gram. Assuming again that the entire blank from the water and calcium carbonate was due to the water and deducting therefore the blank of 0.0124 gram, it is seen that the amount of carbon dioxide found to have been liberated as a result of the action of the calcium carbonate upon the 80 grams of soil, was 0.3256 gram. Owing to rapid evolution of gas on approaching the boiling-point, which necessitated the frequent removal of the lamp, it was feared that some carbon dioxide must have passed through the entire apparatus.

A subsequent test with 40 grams of soil and 8 grams of calcium carbonate was then made. Deducting a blank of $0.0052 \mathrm{gram}$ for the soil and 0.002 gram for the water and calcium carbonate, the amount of carbon dioxide expelled by the soil was found to be 0.1762 gram. This corresponds to $0.35^{24}$ gram for 80 grams of soil as compared with 0.3256 gram in the first test, but in the last test great care was exercised that no carbon dioxide should be lost.

A third test with 40 grams of soil and 4 grams of calcium carbonate yielded 0.178 gram of carbon dioxide. Deducting, as above, a blank of 0.0072 , the amount of carbon dioxide found to have been liberated by the soil was equivalent to 0.3416 gram for 80 grams of soil.

In order to ascertain if differences between soils corresponding 
to those shown by the growth of plants could be detected, a soil (from permanent Plot No. 27) was selected which had been manured the same as the other excepting that it had received its nitrogen in sodium nitrate instead of in ammonium sulphate. A blank test with 40 grams of soil and with the usual amount of water yielded 0.015 gram of carbon dioxide. A test with 40 grams of soil gave, after deduction of the blank just mentioned, 0.1402 gram of carbon dioxide or the equivalent of 0.2804 gram for 80 grams of soil, or much less than was shown by the soil first tested. This accorded with the results secured in plant tests and indicated much greater acidity where nitrogen in ammonium sulphate had been employed than where nitrogen in sodium nitrate was used, or where a basic instead of an acid residue had been left in the soil. In all of the tests thus far made, the operation was stopped after the chief evolution of gas was apparently over and when only a constant and very slight evolution was still noticeable.

To ascertain the effect of longer heating, to grams of soil and 4 grams of calcium carbonate were treated for a much longer time than heretofore. The amount of calcium oxide eliminated, allowing for the blank of 0.015 gram was equivalent for 80 grams of soil to 0.3126 gram as compared with 0.2804 gram where the period of heating was less prolonged. Another test was made under the same conditions, continuing the heating for about the same period as in the preceding instance. The net amount of carbon dioxide driven off, per 80 grams of soil, amounted to 0.322 gram. The same material brought to boiling once more and heated for some time yielded, per 80 grams of soil, 0.032 gram of additional carbon dioxide. Brought to boiling and heated for a third time the further loss for the same amount of soil was equivalent to 0.0256 gram. From these tests it appeared probable that beyond a certain point the attack upon the calcium carbonate became very limited or that a gradual oxidation or else a splitting up of the organic matter was taking place. To ascertain if this would go on at an appreciable rate at ordinary temperatures, a current of air was next passed for two and onehalf hours over the material which had been thus successively heated. As a result it was found that no weighable amount of carbon dioxide had been eliminated. Further heating, as 
before, resulted in a still further elimination of carbon dioxide and an increase in the weight of the absorption tubes. From this it was evident that there was apparently no reasonable time limit within which the elimination of carbon dioxide would be ended, and hence to obtain satisfactory comparative tests with different soils, the period of treatment, temperature, and other conditions must all be kept as uniform as possible. One apparent drawback to the method as it was used, was the necessity of conducting the heating so cautiously, and in consequence, for so long a time, in order that the carbon dioxide might all surely be absorbed, for by doing so the opportunity for the gradual breaking up of the organic matter was much increased. To overcome this objection, in a measure, the use of soda-lime was resorted to as an absorbent for carbon dioxide. By this means, less care was required to insure the absorption of the gas and the period of heating could be materially reduced. Nevertheless the method was still unsatisfactory, and in consequence, it was proposed to operate so as to subject the material to the action of heat a minimum length of time and either measure the volume of the carbon dioxide disengaged or to determine it indirectly by titration with the employment of barium hydroxide, or by estimating the amount of carbonate formed from it and so indirectly the carbon dioxide. Preliminary to this work it was thought wise to ascertain if possible the minimum time that it was necessary to heat the calcium carbonate and soil, in the presence of water, to insure that all of the humus had united with calcium oxide. It is well known that in many cases where soil contains naturally considerable quantities of lime and magnesia, ammonium hydroxide extracts practically no humus until the lime and magnesia have first been removed by acids. Such has been found to be the case in soil from New Mexico and with certain soils from Massachusetts and Rhode Island, which had been treated successively with calcium carbonate. The idea therefore suggested itself that by heating a number of soils with calcium carbonate and water for varying intervals of time, and subsequently testing the residues with ammonium hydroxide, it could be ascertained how long it was necessary to continue the heating in order to get practically all of the humus into an insoluble combination with lime. It was thought that this time 
might be safely taken as the limit for continuing the heating and that the amount of carbon dioxide thus disengaged would serve as a suitable measure of the lime requirement of soils. It was also proposed to test the method with soils which do not react acid, in order that further light might be thrown upon the probable applicability of such a method to the purpose in hand. Unfortunately, routine work has prevented the further carrying on of this investigation. It is a question of too great scientific and practical interest to be laid aside at this point, and it is hoped that opportunity for further pursuit of the question will be afforded in the near future.

COMPARISON OF THE GAIN IN BEETS, RESULTING FROM THE USE OF LIME, WITH THE DETERMINATION OF THE LIME REQUIREMENT OF SOILS MADE BY VARIOUS CHEMICAL METHODS.

The following table shows the amounts of beets produced upon limed and unlimed soil in different sections of Rhode Island. Each plot was manured alike with commercial nitrate of soda, muriate of potash and dissolved bone-black. The table gives the percentage gain from liming, also the amount of humus immediately soluble in ammonium hydroxide, the percentage of "total" humus, the amount of calcium oxide removable by extracting with strong mineral acid, the number of milligrams of nitrogen in the ammonia held in combination by ro grams of soil, the comparative dilution of the ammonium hydroxide extract of a soil of known character to give a degree of coloration corresponding to that exhibited by the extracts from the different soils tested, the amount of calcium oxide removable by carbonated water and the percentage of material in the respective soils which was so coarse as not to pass a sieve with openings $\frac{1}{25}$ of an inch in diameter. Only such material as passed circular openings of this size, was employed in the various tests.

The analytical data in the table were obtained with soil passing a sieve with hole $\frac{1}{25}$ of an inch in diameter. The results are calculated to dry soil. 


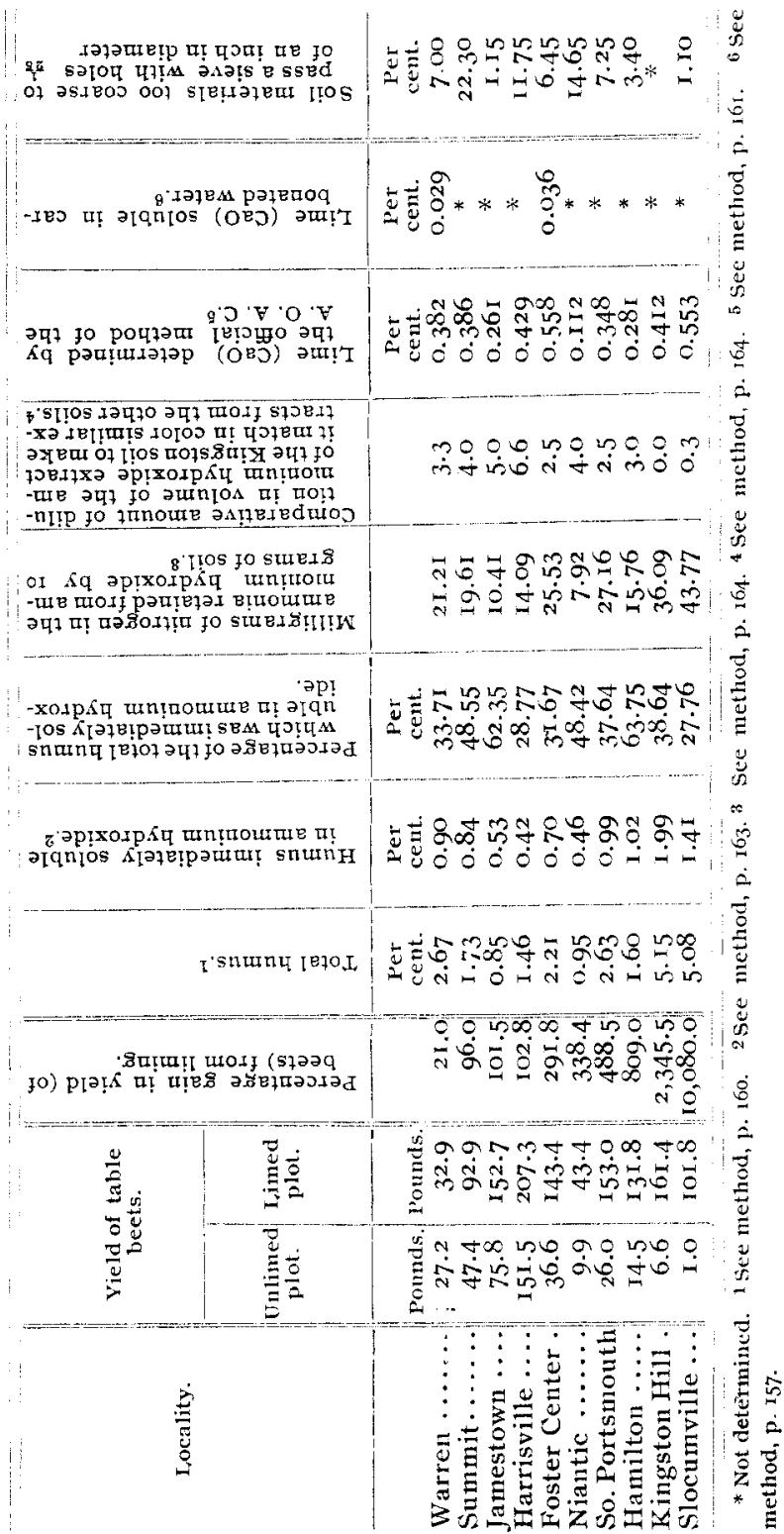


It will be seen that in the foregoing table the Warren soil which was least helped by lime, is placed at the top, the others being arranged in the order of the benefit noted, from top to bottom, with the Slocumville soil, representing a gain of 10,080 per cent. as a result of liming, placed at the foot of the list.

Comparing the percentages of material extracted immediately by treatment with ammonium hydroxide, with the gains from liming, it will be seen that there is no regular correspondence. The tests show a successive decrease in the first three soils while the crop increased. The Niantic soil shows a similar decrease. Of these soils, those at Niantic and Jamestown were exceedingly sandy, while those at Harrisville and Summit were quite gravelly. The result with the Warren soil was unexpectedly high. In the case of the balance of the "heavier" or more compact soils, a successive increase in humus immediately soluble in ammonium hydroxide was noticed, corresponding well, with the exception of the Slocumville soil, with the crop results. In fact this was the only method tried which indicated differences between the So. Portsmouth and Hamilton soils corresponding with those afforded by the crops. It will be noted that the Slocumville soil showed more benefit from liming than that at Kingston, though the latter gave a higher test by this method than the Slocumville soil. For the heavier classes of soils containing naturally considerable quantities of humus, this method gives much promise of usefulness. In the case of the more silicious soils containing but moderate amounts of humus, the method may perhaps indicate with considerable truthfulness the relative lime requirements within the particular class, but when it comes to comparisons of individuals of the one class with those of the other, it is possible that it fails to indicate the truth with sufficient accuracy on account of a considerable amount of the acidity being due more to inorganic, than to organic matter.

In support of this, it may be cited that many of our subsoils, which contain only minimum quantities of organic matter, are decidedly acid, indicating the presence of acid silicates, or other acid inorganic compounds. Mondesir ${ }^{1}$ found that upon the destruction of all of the organic matter in a soil by means of "permanganate" at a temperature below $100^{\circ} \mathrm{C}$., or by combus-

1 Compt. rend., Is, 317, August (1892). 
tion at dull red heat, and after subsequent treatment at ordinary temperature with very dilute hydrochloric or nitric acid, followed by complete removal of these by washing with distilled water and subsequent heating for several hours at from $160^{\circ}$ to I $70^{\circ} \mathrm{C}$., the soil residue was still acid. It decomposed calcium carbonate to some extent at ordinary temperature, and still further upon heating with water to the boiling-point.

It is of interest to note that in the case of the Slocumville soil, where beets almost absolutely refuse to grow without the aid of lime, only 27.76 per cent. of the total humus was immediately soluble in ammonium hydroxide, and in the Kingston soil which stood second in its degree of benefit from liming, but 38.64 per cent. was soluble or much less than in many of the soils where lime proved far less beneficial. The percentage of the total humus which is thus dissolved is not then in any sense a true measure of the lime requirement, though the absolute anounts of humus thus dissolved, have seemed, particularly in our quite heavy soils containing considerable total humus, to correspond with considerable accuracy to the tests with beets.

Though there seems to be no reason to think that there would be any relation between the lime requirement of soils and their total humus on soils of widely divergent character, yet upon soils of analogous mineral origin, it seemed probable that some such relation might exist. The results obtained when plotted in a curve, show, with a few exceptions, the same general trend as those obtained by direct extraction with ammonium hydroxide. In the case of the Jamestown and Harrisville soils the total humus was higher in the former while the amount of humus immediately extracted, was greater in the latter. In the Hamilton soil, the total humus runs too low to accord with the crop test, while the a mount of humus immediately soluble in ammonium hydroxide is greater in the case of that soil than in the one at So. Portsmouth, or in agreement with the results secured with beets. In regard to the Kingston and Slocumville soils, the total humus is slightly less in the latter than in the former, but the results come far nearer agreeing with the crop test, that those obtained by immediate extraction of the humus.

In the case of the determination of the lime (calcium oxide) removable from the soil by digestion with hydrochloric acid, the 
results are of marked interest, since they show in the most striking manner that the data thus secured with our Rhode Island soils furnished no reliable guide to their lime requirements. As marked illustrations, it will be seen that the Foster Center soil which contained $0.55^{8}$ per cent. of calcium oxide, or the greatest quantity of any of the soils examined, gave a gain in crop of 291.8 per cent. as compared with a gain from liming of only $2 \mathrm{I}$ per cent. in the Warren soil, which yielded only 0.382 per cent. of calcium oxide upon extraction with hydrochloric acid. Again the Slocumville soil showed by extraction with the mineral acid 0.553 per cent. of calcium oxide, or but 0.005 per cent. less than the Foster Center soil, and yet it was benefited by lime more than any other soil tested giving a gain from its use amounting to I0,080 per cent. The third highest content of calcium oxide as determined by extraction with hydrochloric acid was shown by the Kingston soil, which yielded 0.4 I 2 per cent., and yet the only soil which showed a greater benefit from liming was that at Slocumville where the percentage of calcium oxide was even much higher than at Kingston. These examples are sufficient to show that even if by this method of analysis considerable lime, even amounting to more than 0.5 per cent., is shown to be present, it may nevertheless be in such combinations that the soil will almost absolutely refuse to produce certain crops until subjected to liming or other alkaline treatment.

The number of milligrams of nitrogen represented by the ammonia retaitsed by the soil, as determined by the method of titration, accords better with the crop results in the case of the Jamestown and Harrisville soils, than those obtained by immediate extraction with ammonium hydroxide. With the Hamilton soil, the result by the latter method agreed more closely with the crop tests, than those by the former, while in the case of the Kingston and Slocumville soils, the agreement with the crop results was more nearly perfect than those by any other method employed.

Only two tests were made by treatment of the soil with carbonated water. The soil which was the more in need of liming showed by this method a greater quantity of calcium oxide removable by the treatment than the other, or just the reverse of what should have been the case if the method were to 


\section{I74 H. J. WHEELER, B. L. HARTWELL, AND C. I. SARGENT.}

prove of value for the purpose in hand. This fact, together with some experience in the same line in connection with other soils, coupled with the small quantities of calcium oxide removable, gave little reason to hope that the method was applicable for ascertaining the true lime requirements of our acid Rhode Island soils.

The tests by means of the comparison of the color of the ammonium hydroxide extract in the case of the four upper soils in the table, viz., those from Warren, Summit, Jamestown, and Harrisville indicate a gradation in the opposite direction from those with beets. The amount of total humus and the ammonia held by the soil as determined by the method of titration, agree, in the case of these soils, more nearly with the crop results. The results with the Foster Center and South Portsmouth soils, though not showing relative differences in the line of those exhibited by the crop, point, when compared with the first four soils in the series, in the same general way in relation to the soil requirements as the tests with beets. The results with the South Portsmouth and Hamilton soils fail to accord between themselves with the beet test, though the result with the latter soil, when compared with the first four of the series, points in the right general direction. Making a general comparison of the data secured with the Kingston and Slocumville soils with those in connection with the soils standing above them in the table, the tests point to the truth as concerns the needs of the soils. Between themselves the tests would indicate a slightly greater need of lime in the Kingston soil than in the Slocumville soil, or just the opposite of the actual experience.

In closing this consideration of these results, it should be stated that it was recognized at the outstart that unfavorable physical conditions might exert a very disturbing influence, and that in consequence a method which takes into account only chemical defects could not be expected to agree in all cases with the crop results. It was hoped, however, to combine physical analyses of the soil with the chemical, with the idea that possibly by a study of both, one might be helped very materially in arriving at a more correct judgment than by the use of either one singly. The resources at disposal have not as yet made it possible for these determinations to be made. There seemed no reason to 
conclude that a physical analysis of the soils only, could come as near revealing their lime requirements as chemical tests, particularly as it had already been abundantly demonstrated ${ }^{\prime}$ that the beneficial action of lime upon our soils is, in a large degree, due to its correcting their prevailing acidity.

\section{SUMMARY.}

In consequence of the recognition of the acidity of many of the upland soils of Rhode Island and their consequent need of lime, it seemed desirable to find some chemical means for satisfactorily revealing their lime requirements, so as to avoid resorting to the slower and more expensive field experiments.

A number of methods have been tried, as follows:

(I) Moistening the soil with water, then bringing it in contact with blue litmus paper and noting with what rapidity and to what extent it reddens the paper as compared with some soil whose character is already well known. This method is highly effective in the hands of a close observer who has had much experience in testing soils of known character.

(2) Treatment of the soil with water to which a little ammonium hydroxide (ammonia water) has been added and noting whether, after settling, the liquid has assumed a dark brown or black appearance. This test applies only where the acidity is due in a considerable measure to acid organic substances. It may not apply in all sections of the country, as shown by Snyder, in Minnesota, but it has thus far proved a very useful and reliable test with Rhode Island and certain other New England and New York soils containing considerable quantities of humus. Gravimetrically applied this is the method of Müntz.

(3) The method employed by Holleman for determining the lime requirement of stiff clay soils in Holland, based upon the amount of lime (calcium oxide) removable by extracting with carbonated water. This method has given little promise of usefulness in testing our upland acid soils.

(4) The method of Tacke for determining the relative acidity of peat (moor) soils of North Germany based upon the amount of carbon dioxide which the acid ingredients of the soil can expel

1 Eighth Annual Report, Rhode Island Agricultural Experiment Station, pp. 232-280 (1895); also Ninth Annual Report, pp. 294-318 (I896). 
from calcium carbonate at ordinary temperatures in an atmosphere of hydrogen. This method has not seemed to be applicable to our acid upland soils.

(5) The determination of the total humus by a modification of the Grandeau method, which consists in removing the lime and magnesia from their combinations with the humus by treatment with dilute hydrochloric acid, and then dissolving the humus in ammonium hydroxide (ammonia water) and estimating the amount dissolved. In our granitic soils containing considerable quantities of humus, this method gives results standing in somewhat definile relation to the lime requirements.

(6) Determinations of the amount of lime (calcium oxide) which can be dissolved by weak hydrochloric acid by digestion at a high temperature for several hours (official method of the A. O. A. C.). This method furnishes no reliable basis for arriving at the lime requirement of our acid upland soils.

(7) Method by titration, based upon measuring the number of milligrams of nitrogen combined as ammonium salts and held by the soil when it is treated in a given way and for a given time with a very dilute solution of ammonium hydroxide.

The results by this method agree more closely with the crop tests than by any other method tried, though it is closely approximated to, by the gravimetric determination of the humus dissolved from the soil by extraction with ammonium hydroxide without the previous removal of the lime and magnesia.

(8) Method based upon the comparison of the color of the extract made from soils by treating directly with ammonia water, with the color of such an extract prepared from a like quantity of soil of known character. It seems probable that where the acidity is due largely to acid organic substances, this method may give fairly good results. The rapidity with which tests may be made by it is an important practical point in its favor as compared with the method as proposed by Müntz.

(9) Method based upon the amount of carbon dioxide expelled by a given amount of soil from calcium carbonate when the two are heated together at the boiling-point in the presence of water. This method gives promise of much value if the period of heating is made uniform and very brief, and if the carbon dioxide liberated is easily and accurately determined. Routine work 
has thus far prevented further attempts to carry out a satisfactory study of this method including the perfection of its details.

LABORATORY OF THE RHONE ISLAND

AGRICULTURAI EXPERIMENT STATION.

\section{NEW BOOKS.}

Axalysis of White Paints. A Collection of Notes on the Chemical Analysis of White and Tinted Paints. BY GEORGE H. ELLIS, B.Sc. Evanston, I1ls.: The Technical Press. 8vo. pp. 57.

The notes under review were originally published in the Paint, Oil and Drug Review, of Chicago, and were prepared and edited by one who has had long practical experience in the technical examination of the products treated. They consist really of a collection of methods for analysis of paints and pigments long used by the author in his daily practice largely devoted to the products of the paint industry, and as the methods have been thoroughly tested and are described in the fullest detail they will be particularly useful to those chemists whose work has given them but limited practice with such products and methods.

With the methods of analysis in each case are presented results obtained by the author in the use of the methods, showing the average composition of the commercial product treated, and thus offers much useful information not easily found elsewhere. The book is commended to those whose duties lead them occasionally in the lines of work here treated and indeed to all needing guidance in the technical examination of pigments and paints.

WM. MCMURTRIE.

The Chemistry of Solls and Fertilizers. By Harry Swyder, B.S., Professor of Agricultural Chemistry, University of Minnesota, and Chemist of the Minnesota Agricultural Experiment Station. Easton, Pa.: The Chemical Publishing Co. 1899. I2 mo, ix +277 pp. Price $\$$ I.50.

We are told in the preface that this book was intended primarily to be used as a text-book in the author's classes. This fact explains the "experiments" and "review questions" which are given at the end of the book, as well as the condensed manner in which it is written.

It should answer admirably the purpose for which it was intended. The subject-matter is well chosen, well arranged, and clearly and concisely stated. 